\title{
Kajian Aktivitas Penambangan Minyak Tua dan Pertanian dalam Upaya Pengembangan Ekonomi Lokal Desa Bangowan Kecamatan Jiken Kabupaten Blora
}

\author{
Sigit Irvan Prasetyo ${ }^{1}$ \\ Jurusan Perencanaan Wilayah dan Kota, Universitas Diponegoro, Semarang
}

Artikel Masuk : 20 Oktober 2014

Artikel Diterima : 15 November 2014

\begin{abstract}
Abstrak: Pengembangan Ekonomi Lokal (PEL) bertujuan menciptakan lapangan kerja baru guna merangsang peningkatan kegiatan ekonomi dan meningkatkan pendapatan masyarakat lokalnya. Desa Bangowan Kecamatan Jiken memiliki dua potensi lokal yaitu potensi pertanian dan pertambangan. Isu di Desa Bangowan meliputi seberapa besar kegiatan PEL dengan memanfaatkan sumberdaya alam, dalam meningkatkan pendapatan, produktivitas dan kesejahteraan penduduk. Tujuan penelitian ini adalah mengkaji produktivitas tenaga kerja dan kesejahteraan masyarakat sebagai penambang dan petani dalam upaya pengembangan ekonomi lokal. Metode yang digunakan adalah metode kuantitatif yang didukung dengan metode kualitatif dengan analisis statistik deskriptif dan analisis regresi ganda. Hasil penelitian menunjukkan belum tercapainya indikator suksesnya PEL, yaitu tidak ada keberdayaan lembaga usaha mikro dan kecil; pola kemitraan PEL yang kurang sempurna; tidak tersedianya fasilitas bisnis klaster; tidak terjadi multiplier effect dari aktivitas penambangan dan pertanian; tidak adanya upaya untuk pengembangan sumberdaya manusia. Kesimpulan yang bisa didapat adalah karakteristik penambang, produktivitas tenaga kerja penambang, kesejahteraan penambang lebih baik daripada petani, kondisi perekonomian penduduk penambang diketahui meningkat.
\end{abstract}

Kata kunci: PEL, penambangan, pertanian

\begin{abstract}
Local Economic Development (LED) that aims to create new jobs in order to stimulate increased economic activity and improve local people's income. Desa Bangowan Kecamatan Jiken has two local potential that is agriculture and mining potential. Isues in Desa Bangowan include how much Local Economic Development activities by using natural resources, to providing new jobs and increase income, productivity and welfare of community. The purpose of study is to assess the productivity of labor and social welfare Desa Bangowan as miners and farmers to support local economic development. The method used is a quantitative method supported by qualitative method with descriptive statistical analysis and multiple regression analysis. Success indicator LED is not achieving that is, no empowerment of micro and small institution; PEL partnership is less perfect; unavailability of business cluster facilities; not occur multiplier effect on society; no efforts for the development of human resources.. The conclusion is miners characteristics, miners labor productivity, welfare miners are better than farmers, economy of miners is known increasing.
\end{abstract}

Keywords: LED, mining, agriculture

\footnotetext{
${ }^{1}$ Korespondensi Penulis: Jurusan Perencanaan Wilayah dan Kota, Universitas Diponegoro, Semarang, Indonesia Email: sigit.irvan.p@gmail.com
} 


\section{Pendahuluan}

Pembangunan ekonomi yang berbasis sumber daya alam yang tidak memperhatikan aspek kelestarian lingkungan akan berdampak negatif pada lingkungan itu sendiri. Sehingga diperlukan suatu pembangunan yang mampu menjawab bagaimana keberlanjutan kedepannya (Jaya, 2004:1). Pembangunan berkelanjutan adalah pembangunan yang memenuhi kebutuhan generasi saat ini tanpa mengurangi kemampuan generasi mendatang untuk memenuhi kebutuhan mereka sendiri. Pembangunan berkelanjutan dilihat dari segi spasial, mencakup pembangunan wilayah yang dikenal sebagai Pengembangan Ekonomi Lokal (PEL). Pengembangan Ekonomi Lokal (PEL) merupakan proses kemitraan antara pemerintah daerah dengan stakeholders termasuk swasta dalam mengelola sumberdaya alam, sumberdaya manusia maupun kelembagaan melalui pola kemitraan dengan tujuan mendorong pertumbuhan kegiatan ekonomi daerah dan menciptakan pekerjaan baru (Munir, 2008:19). Tujuan dari PEL adalah menciptakan lapangan kerja baru guna merangsang peningkatan kegiatan ekonomi dan meningkatkan pendapatan masyarakat lokalnya.

Dari beberapa definisi tersebut dapat diketahui dalam proses Pengembangan Ekonomi Lokal yang berkelanjutan, menitik beratkan pada sumberdaya manusia yang terlibat. Dimana Pengembangan Ekonomi Lokal berkelanjutan diharapkan mampu menciptakan lapangan kerja baru, merangsang peningkatan kegiatan ekonomi, meningkatkan pendapatan masyarakat lokal, sehingga mampu meningkatkan produktivitas dan kesejahteraan masyarakat lokal. Desa Bangowan Kecamatan Jiken memiliki dua potensi lokal pada sumberdaya alamnya, yaitu potensi pertanian dan pertambangan minyak tua. Dampak adanya potensi penambangan dan pertanian tersebut, tentu berbeda baik antara penambang dan petani. Perbedaan dampak tersebut dapat ditinjau dari tingkat produktivitas dan tingkat kesejahteraannya.

Penekanan terhadap produktivitas dan kesejahteraan penduduk lokal, disebabkan dalam proses pembangunan ekonomi sumbedaya manusia merupakan salah satu faktor produksi yang paling mendominasi (Simanjuntak, 1985: 13). Selain itu sumberdaya manusia berperan sebagai agen pembangunan, pemerintah, pengusaha maupun NGO, yang harus bekerjasama membangun kekuatan ekonomi lokal (Khomsiyah, 2013: 5-6). Sehingga perlu suatu kajian khusus mengenai keterlibatan masyarakat Desa Bangowan dalam Pengembangan Ekonomi Lokal berkelanjutan, yaitu sebagai penambang dan petani.

Jika dikaitkan dengan tujuan Pengembangan Ekonomi Loakal, maka isu terbesar meliputi seberapa besar kegiatan Pengembangan Ekonomi Lokal mampu menyediakan lapangan kerja baru dan meningkatkan pendapatan penduduk sehingga kesejahteraan dan produktivitas masyarakat meningkat. Dikarenakan Desa Bangowan memiliki potensi sumberdaya minyak tua dan pertanian, yang dijadikan sebagai faktor Pengembangan Ekonomi Lokal dan fokus PEL adalah manusianya maka penelitian ini menitikberatkan pada penghitungan produktivitas tenaga kerja dan kesejahteraan penduduk sebagai petani dan penambang. Sehingga hasil yang didapat diharapkan mampu menjawab isu terbesar terkait Pengembangan Ekonomi Lokal berkelanjutan di Desa Bangowan. Dari dua inti pokok permasalahan tersebut dikembangkan suatu pertanyaan penelitian, yaitu: "Seberapa besar peranan aktivitas penambangan dan pertanian terhadap produktivitas tenaga kerja dan kesejahteraan masyarakat dalam upaya pengembangan ekonomi lokal di Desa Bangowan?"

Tujuan dari penelitian ini adalah mengkaji peranan penambangan dan pertanian terhadap produktivitas tenaga kerja dan kesejahteraan masyarakat dalam upaya pengembangan ekonomi lokal di Desa Bangowan Kecamatan Jiken Kabupaten Blora. Adapun Sasaran dalam penelitian ini meliputi : 
- Identifikasi kondisi karakteristik wilayah penambangan dan pertanian Desa Bangowan;

- Identifikasi karakteristik tenaga kerja penambang dan pertanian di Desa Bangowan;

- Analisis produktivitas tenaga kerja penambang dan petani di Desa Bangowan;

- Analisis kesejahteraan tenaga kerja penambang dan petani di Desa Bangowan;

- Mengkaji karakteristik tenaga kerja, produktivitas dan kesejahteraan masyarakat dalam upaya pengembangan ekonomi lokal Desa Bangowan.

Ruang lingkup wilayah dalam penelitian ini dibatasi pada lingkup Desa Bangowan Kecamatan Jiken Kabupaten Blora. Adapun peta administrasinya sebagai berikut:

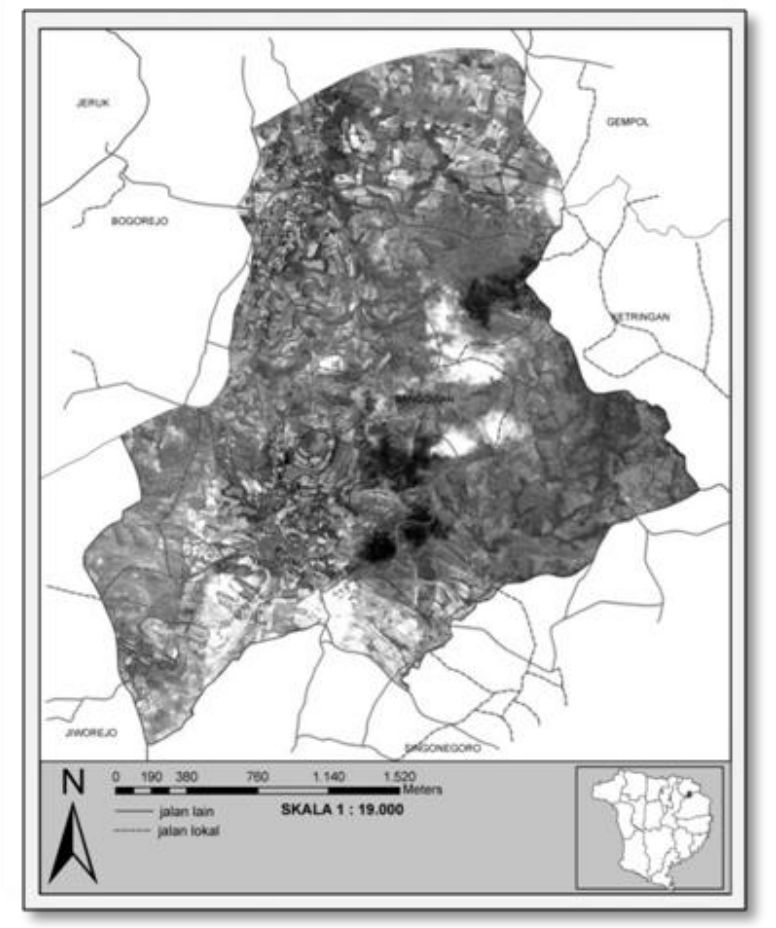

Sumber: Bappeda Kabupaten Blora, 2014

\section{Gambar 1. Peta Administrasi Desa Bangowan}

\section{Metodologi Penelitian}

\section{Metode Pengumpulan Data}

Pengumpulan data pada dasarnya dapat dilakukan dalam berbagai setting, sumber, dan cara. Jika dilihat dari sumbernya data dikelompokkan menjadi sumber primer dan sumber sekunder (Sugiyono:2008). Dilihat dari segi atau teknik pengumpulan data dikelompokkan menjadi wawancara, kuesioner, observasi dan gabungan.

Data yang dipakai dalam penelitian merupakan data primer dan data sekunder.

- Wawancara.

Teknik wawancara digunakan untuk mengetahui hal - hal dari responden yang lebih mendalam dan jumlah tesponden terlampau sedikit (Sugiyono: 2008).

- Kuesioner

Jika disangkutkan dengan penelitian yang dilakukan pertanyaan yang ada pada kuesioner berasal dari indikator - indikator per variabel yang telah dirumuskan 
Tabel 1. Variabel Dan Indikator Penelitian

\begin{tabular}{|c|c|}
\hline Variabel Penelitian & Indikator Penelitian \\
\hline 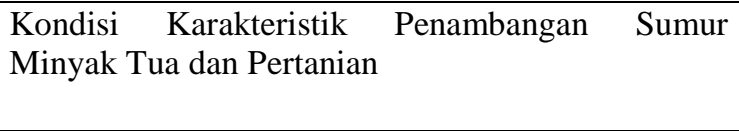 & $\begin{array}{l}\text { - Sistem Kerja } \\
\text { - Kondisi pekerja } \\
\text { - Kondisi lapangan }\end{array}$ \\
\hline Produktivitas tenaga kerja & - Output (hasil kerja/jam) \\
\hline Upah pekerja & - Upah pokok Lamanya waktu bekerja \\
\hline Pengalaman kerja & - Lamanya waktu bekerja \\
\hline Pendidikan & - Lamanya pendidikan formal \\
\hline Jenis kelamin & - Jenis kelamin pekerja \\
\hline Umur & - Umur saat dalam bekerja \\
\hline Alokasi waktu kerja & - Lamanya waktu (jam) dalam bekerja per hari \\
\hline Kebutuhan Primer & $\begin{array}{l}\text { - Sandang } \\
\text { - Pangan } \\
\text { - Rumah } \\
\end{array}$ \\
\hline Kebutuhan Sekunder & $\begin{array}{l}\text { - Kondisi Lantai Rumah } \\
\text { - Kondisi Dinding Rumah } \\
\text { - Kebutuhan Perabot Rumah Tangga } \\
\text { - Kebutuhan Kesehatan } \\
\text { - Kebutuhan MCK } \\
\end{array}$ \\
\hline Kebutuhan Tersier & $\begin{array}{l}\text { - Kepemilikan Sepeda Motor } \\
\text { - Kepemilikan Emas } \\
\text { - Kepemilikan Hewan Ternak }\end{array}$ \\
\hline Pengembangan Ekonomi Lokal & $\begin{array}{l}\text { - Pola kemitraan PEL (Pemerintah Daerah, } \\
\text { - Swasta, Masyarakat Lokal) } \\
\text { - Keberadaan Upaya Pengembangan SDM } \\
\text { - Keberdayaan lembaga usaha mikro dan kecil } \\
\text { - Fasilitas bisnis cluster dan Multiplier effect } \\
\text { - Perluasan kesempatan kerja } \\
\text { - Tingginya pendapatan masyarakat } \\
\text { - Tingginya produktivitas tenaga kerja } \\
\text { - Tingginya Kualitas hidup atau kesejahteraan }\end{array}$ \\
\hline
\end{tabular}

- $\quad$ Sampel Penelitian

Teknik sampel yang digunakan adalah Probability sampling yaitu teknik pengambilan sampel yang memberikan peluang yang sama bagi setiap unsur populasi untuk dipilih menjadi sampel (Sugiyono,2010:63). Populasi meliputi pada aktivitas penambangan sumur minyak tua dan populasi pada aktivitas pertanian di Desa Bangowan Kecamatan Jiken. Karena kedua populasi dalam lingkup yang homogen yaitu sebagai tenaga kerja, maka sampel pada kedua aktivitas tersebut dianggap sebagai sampel yang homogen sehingga menggunakan teknik Homogram Harry King (Sugiyono, 2010:72).

Tabel 2. Penentuan Sampel Penelitian

\begin{tabular}{c|c|c|c|c}
\hline Jenis Aktivitas & Populasi & Tingkat Kesalahan & Persentase Sampel & Sampel \\
\hline Penambangan & 140 & \multirow{2}{*}{$10 \%$} & $30 \%$ & 42 \\
\cline { 1 - 2 } \cline { 4 - 5 } Pertanian & 1260 & & $4 \%$ & 51 \\
\hline
\end{tabular}




\section{Metode Analisis Data}

- Statistik Deskriptif

Statistik deskriptif merupakan statistik yang memiliki fungsi untuk mendeskripsikan atau memberi gambaran terhadap objek yang sedang diteliti melalui data sampel atau populasi sebagaimana adanya tanpa melakukan analisis dan membuat kesimpulan yang berlaku untuk umum (Sugiyono:2010).

Dalam statistik deskriptif penyajian data menggunakan dengan tabel biasa, tabel distribusi frekuensi, grafik garis maupun batang, pie chart, pictogram, penjelasan kelompok melalui mean, median, modus dan variasi kelompok melalui rentang dan simpangan baku (Sugiyono:2010).

- $\quad$ Regresi Ganda

Analisis regresi pada dasarnya digunakan untuk memprediksikan seberapa jauh perubahan nilai dari variabel dependen, bila nilai dari variabel independen dimanipulasi (Sugiyono, 2010). Selain itu dapat mengetahui bagaimana hubungan antara variabel independen dengan dependen. Seperti yang diketahui jika hubungan antar variabel dapat diketahui dari besar kecilnya koefisien korelasi yang dihasilkan dari analisis korelasi. (Sugiyono, 2010):

$$
Y=\propto+\beta_{1} X_{1}+\beta_{2} X_{2}+\beta_{3} X_{3}+\beta_{4} X_{4}+\beta_{5} X_{5}+\beta_{6} X_{6}
$$

Dimana :

Y :Produktivitas Tenaga Kerja

$\alpha$ : Bilangan Konstanta

$\mathrm{X}_{1}$ : Jenis Kelamin

$\mathrm{X}_{2}$ : Umur

$\mathrm{X}_{3}$ : Alokasi Waktu Kerja

$\mathrm{X}_{4}$ : Pengalaman Kerja

$\mathrm{X}_{5}$ : Upah

$\mathrm{X}_{6}$ : Pendidikan Terakhir

$\beta_{1}, \beta_{2}, \beta_{3}, \beta_{4}, \beta_{5}, \beta_{6}$ : Koefisien Masing - masing Variabel

\section{Temuan dan Kajian Studi}

Subbab ini terbagi menjadi dua yaitu temuan studi dan keterkaitan temuan studi terhadap upaya Pengembangan Ekonomi Lokal. Sehingga didapat gambaran bagaimana proses dan pencapaian akhir PEL di Desa Bangowan dengan memanfaatkan sumberdaya alam yang ada.

Tabel 3. Temuan Studi Penelitian

\begin{tabular}{l|l}
\hline \multicolumn{1}{c|}{ Penambang } & \multicolumn{1}{c}{ Petani } \\
\hline $\begin{array}{l}\text { Timbulnya kesempatan kerja baru sebagai } \\
\text { penambang (140 tenaga kerja) }\end{array}$ & $\begin{array}{l}\text { Kesempatan kerja sebagai petani telah ada sejak } \\
\text { puluhan tahun (1.260 pekerja) }\end{array}$ \\
\hline $\begin{array}{l}\text { Tidak ada usaha mikro dan kecil penunjang } \\
\text { penambangan }\end{array}$ & $\begin{array}{l}\text { Tidak ada usaha mikro dan kecil penunjang } \\
\text { pertanian }\end{array}$ \\
\hline $\begin{array}{l}\text { Pola kemitraan PEL hanya antara pemerintah } \\
\text { daerah dan investor swasta }\end{array}$ & Tidak ada pola kemitraan PEL aktivitas pertanian \\
\hline Tidak ada upaya khusus dalam pengembangan & Tidak ada upaya khusus dalam pengembangan \\
\hline
\end{tabular}




\begin{tabular}{|c|c|}
\hline Penambang & Petani \\
\hline sumberdaya manusia & sumberdaya manusia \\
\hline Pekerja laki - laki lebih mendominasi & Pekerja laki - laki lebih mendominasi \\
\hline Rata - rata umur penambang 35 tahun & Rata - rata umur penambang 43 tahun \\
\hline Rata - rata alokasi waktu kerja 9 jam/hari & Rata - rata alokasi waktu kerja 5 jam/hari \\
\hline Rata - rata pengalaman kerja $0-5$ tahun & Rata - rata pengalaman kerja $>20$ tahun \\
\hline Rata - rata upah pokok Rp435.000 & Rata - rata upah pokok Rp240.000 \\
\hline $\begin{array}{l}\text { Rata - rata pendidikan yang ditamatkan } 9-10 \\
\text { tahun }\end{array}$ & Rata - rata pendidikan yang ditamatkan 6 tahun \\
\hline $\begin{array}{l}\text { Rata - rata produktivitas tenaga kerja } 13,4 \\
\text { liter/jam }\end{array}$ & Rata - rata produktivitas tenaga kerja $1,3 \mathrm{~kg} / \mathrm{jam}$ \\
\hline $\begin{array}{l}\text { Koefisien determinansi (R-square) sebesar } 0.692 \text {. } \\
\text { Artinya variabel independen mempengaruhi } \\
\text { produktivitas tenaga kerja penambang sebanyak } \\
69,2 \% \text {. }\end{array}$ & $\begin{array}{l}\text { Koefisien determinansi (R-square) sebesar } 0.413 \text {. } \\
\text { Artinya variabel independen mempengaruhi } \\
\text { produktivitas tenaga kerja petani sebanyak } 41,3 \% \text {. }\end{array}$ \\
\hline $\begin{array}{l}\text { - Variabel Jenis Kelamin (X1), Alokasi Waktu } \\
\text { Bekerja (X3), Pengalaman Kerja (X4), Upah } \\
\text { Pokok (X5) berpengaruh terhadap produktivitas } \\
\text { tenaga kerja penambang (Y) } \\
\text { - Variabel Umur (X2), Pendidikan terakhir (X6) } \\
\text { tidak mempengaruhi produktivitas tenaga kerja } \\
\text { penambang (Y) }\end{array}$ & $\begin{array}{l}\text { - Variabel Alokasi Waktu Bekerja (X3), } \\
\text { berpengaruh terhadap produktivitas tenaga kerja } \\
\text { penambang (Y) } \\
\text { - Variabel Jenis Kelamin (X1), Umur (X2), } \\
\text { Pengalaman Kerja (X4), Upah Pokok } \\
\text { (X5)Pendidikan terakhir (X6) tidak } \\
\text { mempengaruhi produktivitas tenaga kerja petani } \\
\text { (Y) }\end{array}$ \\
\hline $\begin{array}{l}\text { Tingkat pemenuhan kebutuhan primer penambang } \\
\text { terpenuhi. }\end{array}$ & $\begin{array}{l}\text { Tingkat pemenuhan kebutuhan primer petani } \\
\text { terpenuhi }\end{array}$ \\
\hline $\begin{array}{l}\text { Pemenuhan kebutuhan sekunder penambang } \\
\text { terpenuhi. } \\
\text { - Kondisi lantai rumah, rata - rata ubin dan plester } \\
\text { semen. } \\
\text { - Sebanyak } 71 \% \text { responden memiliki dinding } \\
\text { rumah tembok semen. } \\
\text { - Kebutuhan perabotan rumah tangga, kesehatan, } \\
\text { MCK, } 90 \text { - } 100 \% \text { responden menyatakan } \\
\text { terpenuhi. }\end{array}$ & $\begin{array}{l}\text { Pemenuhan kebutuhan sekunder penambang kurang } \\
\text { terpenuhi. } \\
\text { - } 53 \% \text { responden menyatakan kondisi lantai rumah } \\
\text { masih tanah. } \\
\text { - } 73 \% \text { kondisi dinding rumah masih kayu. } \\
\text { - Kebutuhan perabotan rumah tangga, kesehatan, } \\
\text { MCK, } 80 \text { - } 90 \% \text { responden menyatakan } \\
\text { terpenuhi. }\end{array}$ \\
\hline $\begin{array}{l}\text { Tingkat pemenuhan kebutuhan tersier penambang } \\
\text { ditinjau dari } \\
\text { - Kepemilikan sepeda motor }>80 \% \text { reponden } \\
\text { menyatakan memiliki. } \\
\text { - Kepemilikan perhiasan emas dan hewan ternak } \\
\text { sebanyak } 50-60 \% \text { menyatakan tidak memiliki. }\end{array}$ & $\begin{array}{l}\text { Tingkat pemenuhan kebutuhan tersier penambang } \\
\text { ditinjau dari } \\
\text { - Kepemilikan sepeda motor }>69 \% \text { reponden } \\
\text { menyatakan memiliki. } \\
\text { - Kepemilikan perhiasan emas dan hewan ternak } \\
\text { sebanyak 55\% menyatakan tidak memiliki. }\end{array}$ \\
\hline
\end{tabular}

Tabel 4. Keterkaitan Temuan Studi Terhadap Upaya Pengembangan Ekonomi Lokal Desa Bangowan

\begin{tabular}{|c|c|c|}
\hline Indikator Suksesnya PEL & Penambang & Petani \\
\hline \multicolumn{3}{|c|}{ Ditinjau Dari Proses Pelaksanaan PEL } \\
\hline $\begin{array}{l}\text { Pola kemitraan PEL } \\
\text { (Pemerintah Daerah, Swasta, } \\
\text { Masyarakat Lokal) }\end{array}$ & $x$ & $x$ \\
\hline - Keberadaan Upaya & $x$ & $\times$ \\
\hline
\end{tabular}




\begin{tabular}{|c|c|c|c|c|}
\hline Indikator Suksesnya PEL & \multicolumn{2}{|c|}{ Penambang } & \multicolumn{2}{|c|}{ Petani } \\
\hline \multicolumn{5}{|l|}{ Pengembangan SDM } \\
\hline $\begin{array}{l}\text { - Keberdayaan lembaga usaha } \\
\text { mikro dan kecil }\end{array}$ & \multicolumn{2}{|c|}{$x$} & \multicolumn{2}{|c|}{$x$} \\
\hline $\begin{array}{l}\text { - Fasilitas bisnis cluster dan } \\
\text { Multiplier effect }\end{array}$ & \multicolumn{2}{|c|}{$x$} & \multicolumn{2}{|c|}{$x$} \\
\hline \multicolumn{5}{|l|}{ Ditinjau Dari Tujuan PEL } \\
\hline - Perluasan kesempatan kerja & \multicolumn{2}{|c|}{$\mathrm{O}$} & \multicolumn{2}{|c|}{$\mathrm{O}$} \\
\hline $\begin{array}{l}\text { - Tingginya pendapatan } \\
\text { masyarakat }\end{array}$ & \multicolumn{2}{|c|}{$\mathrm{O}$} & \multicolumn{2}{|c|}{$x$} \\
\hline $\begin{array}{l}\text { - Tingginya produktivitas tenaga } \\
\text { kerja }\end{array}$ & \multicolumn{2}{|c|}{$\mathrm{O}$} & \multicolumn{2}{|c|}{$x$} \\
\hline $\begin{array}{l}\text { - Tingginya Kualitas hidup atau } \\
\text { kesejahteraan }\end{array}$ & \multicolumn{2}{|c|}{$\mathrm{O}$} & \multicolumn{2}{|c|}{$x$} \\
\hline \multirow[b]{2}{*}{$\begin{array}{l}\text { KETERANGAN : } \\
\text { O }=\text { Ada/Terjadi } \\
\times \quad=\text { Tidak Ada/Tidak terjadi }\end{array}$} & $\begin{array}{l}\text { Tercapainya } \\
\text { Tujuan PEL }\end{array}$ & $\begin{array}{c}\text { Belum } \\
\text { Tercapainya } \\
\text { Proses } \\
\text { Pelaksanaan } \\
\text { PEL yang } \\
\text { benar }\end{array}$ & $\begin{array}{c}\text { Belum } \\
\text { Tercapainya } \\
\text { Tujuan PEL } \\
\text { secara } \\
\text { sempurna }\end{array}$ & $\begin{array}{c}\text { Belum } \\
\text { Tercapainya } \\
\text { Proses } \\
\text { Pelaksanaan } \\
\text { PEL yang } \\
\text { benar }\end{array}$ \\
\hline & \multicolumn{2}{|c|}{$\begin{array}{l}\text { Pengembangan Ekonomi Lokal } \\
\text { dengan pemanfaatan sumberdaya } \\
\text { minyak tua belum mampu } \\
\text { menjamin keberlanjutan } \\
\text { masyarakatnya. Sebab, indikator } \\
\text { proses pelaksanaan PEL belum } \\
\text { tercapai. Sumur minyak tua hanya } \\
\text { memberikan manfaat bagi } \\
\text { penambangnya saja. Dan belum } \\
\text { memberikan manfaat baik untuk } \\
\text { masyarakat non-penambang. Hal } \\
\text { ini ditinjau dari belum adanya } \\
\text { pengembangan SDM, tidak } \\
\text { adanya usaha mikro dan kecil, } \\
\text { tidak adanya multiplier effect yang } \\
\text { timbul dari penambangan. }\end{array}$} & \multicolumn{2}{|c|}{$\begin{array}{l}\text { Aktivitas pertanian hanya } \\
\text { mampu mewujudkan tujuan } \\
\text { PEL dalam kesempatan kerja. } \\
\text { Walaupun pertanian } \\
\text { menyumbang } 1.260 \text { tenaga } \\
\text { kerja petani, kenyataanya tidak } \\
\text { mampu mewujudkan proses } \\
\text { dan tujuan PEL dengan baik. } \\
\text { Hal ini mengindikasikan jika } \\
\text { pertanian belum menjadi fokus } \\
\text { PEL Desa Bangowan. } \\
\text { Pertanian hanya bersifat mata } \\
\text { pencaharian yang digunakan } \\
\text { penduduk untuk mampu } \\
\text { mencukupi kehidupan sehari- } \\
\text { hari. Tanpa memikirkan } \\
\text { kebutuhan masa mendatang. }\end{array}$} \\
\hline
\end{tabular}

\section{Kesimpulan dan Rekomendasi}

\section{Kesimpulan}

1. Karakteristik penambang jauh lebih baik daripada karakteristik petani.

2. Produktivitas tenaga kerja pada aktivitas penambangan sumur minyak tua diketahui lebih besar daripada produktivitas tenaga kerja pada aktivitas pertanian.

3. Aktivitas penambangan mendorong terciptanya lapangan kerja baru sejak tahun 2009 di penambangan.

4. Kondisi perekonomian penduduk sebagai penambang diketahui meningkat. 
5. Kesejahteraan penambang diketahui lebih baik daripada petani. Hal ini ditinjau dari pemenuhan kebutuhan sekunder dan tersier. Dimana kondisi dinding rumah, lantai rumah dan kepemilikan sepeda motor penambang lebih baik daripada petani.

6. Proses Pengembangan Ekonomi Lokal Desa Bangowan dengan pemanfaatan sumberdaya minyak tua dan pertanian, belum berjalan sempurna. Hal ini ditinjau dari belum tercapainya indikator suksesnya PEL, yaitu:

- Tidak adanya keberdayaan lembaga usaha mikro dan kecil guna menunjang penambangan dan pertanian

- Pola kemitraan PEL (Pemerintah Daerah, Swasta, Masyarakat Lokal) yang kurang sempurna pada aktivitas penambangan. Dimana hanya melibatkan pemerintah daerah dan swasta saja. Dan tidak adanya pola kemitraan pada aktivitas pertanian.

- Tidak tersedianya fasilitas bisnis cluster baik dalam penambangan maupun pertanian

- Tidak terjadi Multiplier effectterhadap masyarakat dari aktivitas penambangan dan pertanian di Desa Bangowan

- Tidak adanya upaya untuk pengembangan sumberdaya manusia pada aktivitas penambangan dan pertanian di Desa Bangowan

7. Pengembangan Ekonomi Lokal dengan memanfaatkan penambangan minyak tua lebih efektif daripada memanfaatkan pertanian. Sebab dengan pemanfaatan sumberdaya minyak tua mampu meningkatkan pendapatan, produktivitas tenaga kerja dan kesejahteraan masyarakat.

\section{Rekomendasi}

1. Penerapan Pengembangan Ekonomi Lokal (PEL) di Desa Bangowan dengan mengaplikasikan indikator - indikator yang ada yaitu :

- Pola kemitraan PEL (Pemerintah Daerah, Swasta, Masyarakat Lokal)

- Adanya keberadaan upaya pengembangan SDM

- Adanya keberdayaan lembaga usaha mikro dan kecil

- Memfasilitasi bisnis cluster dan Multiplier effect

- Perluasan kesempatan kerja

- Meningkatkan pendapatan masyarakat

- Meningkatkan produktivitas tenaga kerja

- Meningkatkan Kualitas hidup atau kesejahteraan

2. Keterlibatan masyarakat dalam pola kemitraan PEL yang terdiri dari pemerintah daerah, investor swasta, dan masyarakat lokal.

3. Peningkatan faktor - faktor produktivitas tenaga kerja pertanian, pengadaan pelatihan - pelatihan atau sosialisasi tentang kegiatan pertanian yang baik dan produktif

4. Pemberian dana atau modal terhadap kegiatan pertanian Desa Bangowan. Modal ini dapat berasal dari tabungan masyarakat atau dana pemerintah.

5. Pembentukan koperasi khusus untuk para penambang, sebagai wadah untuk memutarkan pendapatan dari hasil penambangan

6. Percepatan pengaktifan titik sumur minyak tua yang lain di Desa Bangowan. Agar mampu menyerap tanaga kerja penduduk Desa Bangowan lebih banyak ke aktivitas penambangan. 


\section{Ucapan Terima Kasih}

Penulis ingin mengucapkan terima kasih kepada Dr.-Ing. Wiwandari Handayani, ST, MT, MPP karena telah memberikan bimbingan kepada penulis dalam penelitian ini. Ucapan terima kasih juga diberikan kepada pihak-pihak yang telah membantu memberikan informasi dan data-data terkait yang mendukung analisis penulis.

\section{Daftar Pustaka}

BPS Kabupaten Blora. 2012. Kecamatan Jiken dalam Angka 2013. Kantor Statistik Kabupaten Blora ESDM .2008. Peraturan Menteri ESDM No.1 tahun 2008. Menteri Ekonomi Sumber Daya Manusia.

Simanjuntak, Payaman J. et.al. 1985. Produktivitas dan Tenaga Kerja Indonesia. Anonim

Jaya, Askar. 2004. "Konsep Pembangunan Berkelanjutan (Sustainable Development)", dalam Laporan Penelitian Pengantar Falsafah Sains (PPS-702) Program S3 Institut Pertanian Bogor. Bogor

Khomsiyah, et.al. 2013. "Membangun Kemandirian Ekonomi Melalui Pengembangan Ekonomi Lokal Berkelanjutan Untuk Meningkatkan Kualitas Hidup Manusia”, dalam Laporan Penelitian Konvensi Kampus IX dan Temu Tahunan XV Forum Rektor Indonesia. Semarang.

Munir, Risfan et.al. 2008. Pengembangan Ekonomi Lokal Partisipatif: Masalah Kebijakan dan Panduan Pelaksanaan Kegiatan. Local Governence Support Program (LGSP).

Sugiyono. 2008. Statistika Untuk Penelitian. Bandung: Alfabeta

2010. Statistika Untuk Penelitian. Bandung: Alfabeta

UU Indonesia. 2001. Undang-Undang Republik Indonesia Nomor 22 Tahun 2001 Tentang Minyak Dan Gas Bumi. Pemerintah Republik Indonesia. 
230 Kajian Aktivitas Penambangan Minyak Tua dan Pertanian dalam ...

JURNAL WILAYAH DAN LINGKUNGAN, 2 (3), 221-230 